\title{
Effect of mode shift from car to light rail on personal exposure: A controlled experiment
}

\author{
Andy Hong \\ *Address correspondence to: Andy Hong, PhD, The George Institute for Global Health, Nuffield \\ Department of Women's \& Reproductive Health, University of Oxford, Hayes House, 75 George \\ Street, Oxford OX12BQ, United Kingdom \\ E-mail: andyhong@gmail.com, andy.hong@georgeinstitute.ox.ac.uk
}

This paper was published in Atmospheric Environment

Hong, Andy. 2019. Effect of mode shift from car to light rail on personal exposure: A controlled experiment. Atmospheric Environment, 196: 53-65

For the final published version, please use this DOI to locate the paper:

https://doi.org/10.1016/j.atmosenv.2018.10.004 


\title{
Effect of mode shift from car to light rail on personal exposure: A controlled experiment
}

\begin{abstract}
Light rail transit (LRT) has a reputation for being cleaner and healthier than automobiles. However, few studies have examined the effects of mode shift from automobile to LRT. This paper investigates to what extent mode shift from car to LRT can reduce personal exposure to $\mathrm{PM}_{2.5}$, BC, and UFP. Simultaneous measurements on LRT and automobile were conducted under four plausible commuting scenarios in Los Angeles, California from October to November in 2014. As a robustness check, Monte Carlo simulations were performed to test the effects of confounding factors. Under the closed ventilation and low traffic condition, personal exposure measurements inside LRT were significantly higher than in automobile for $\mathrm{BC}(+40 \%, p<0.01)$ and UFP $(+27 \%, p<0.01)$. However, under the open ventilation and high traffic condition, personal exposure was significantly lower in LRT than in automobile for $\mathrm{PM}_{2.5}(-38 \%, p<0.01)$; BC $(-68 \%, p<0.01)$; and UFP $(-141 \%, p<0.01)$. Results of the Monte Carlo simulations suggest that other factors, such as vehicle fan strength, vehicle speed, and vehicle age, appear to have marginal effects on personal exposure. These results demonstrate that the effect of mode shift from car to LRT can be significantly altered by ventilation settings and travel route choices. Results inform future research and policy about the importance of incorporating ventilation and traffic microenvironments for assessing the health effects of a mode switch from car to LRT.
\end{abstract}

\section{Highlights}

- Examined the effect of mode shift from car to LRT using simultaneous measurements

- Developed Monte Carlo simulations to test the effects of confounding factors

- The effect of mode shift was driven by ventilation and traffic condition

- Other factors, such as vehicle age, speed, and fan strength, were less influential

Keywords: mode shift; personal exposure; simultaneous measurement; Monte Carlo simulation; ventilation; microenvironment 


\section{1. INTRODUCTION}

2 Light rail transit (LRT) has a long-standing reputation as a clean and healthy transportation. It has been generally known that LRT offers intermediate health benefits in terms of physical

4 activity (Brown et al., 2015; Hong et al., 2016) and air quality (Chen and Whalley, 2012; Saxe et

5 al., 2015). When it comes to air pollution, transportation literature often reports that electricitypowered rail system contributes to reducing traffic emissions because it consumes less energy and generates less emissions per passenger kilometer compared to automobiles (TRB, 2011). When it comes to air pollution exposure, however, benefits of LRT over automobiles remain less clear, with mixed results reported in the literature (Morabia et al., 2010; Zuurbier et al., 2010).

Previous studies of commuter exposure can be broadly defined into two groups: i) multi modal studies that compare exposure differences across multiple travel modes; and ii) single mode studies that focus on exposure assessment of a specific travel mode. Multi modal studies have generally shown that active travel modes have higher exposure than less active modes (Kaur et al., 2005). However, a growing body of research suggests that modal difference alone may not fully explain the difference in personal exposure (Ham et al., 2017; Kaur et al., 2007; Knibbs et al., 2011). Differences caused by a specific mode can be trumped by other factors, such as ventilation and traffic microenvironments. Especially, ventilation setting of a vehicle could be a deciding factor because personal exposure is largely influenced by how much outside pollutants penetrate into the vehicle (Chaney et al., 2017; Ham et al., 2017; Quiros et al., 2013).

On the other hand, single mode studies offer more nuanced understanding of the mechanism by which modal differences might affect air pollution exposure. For example, in-vehicle exposure studies suggest that pollutant concentrations inside vehicles can be highly variable (Fruin et al., 2011). Even for the same type of vehicle, in-vehicle exposure may differ significantly depending on ventilation settings, roadway types, traffic condition, and vehicle and driving characteristics

27 (Fruin et al., 2011; Hudda et al., 2012; Knibbs et al., 2009; Ott et al., 2008). Previous studies of in-vehicle exposure indicate that both on-road concentrations and penetration rates of outside

29 pollutants into vehicles are equally important factors (Hudda et al., 2012; Knibbs et al., 2010).

30 Therefore, an accurate assessment of in-vehicle exposures would require the consideration of key

31 factors related to driver and vehicle characteristics as well as transport microenvironments. 
33 Notably, few empirical studies have systemically examined the effects of mode shift from car to

34 rail transit on air pollution exposure. One study from Salt Lake, Utah conducted simultaneous

35 measurements of $\mathrm{PM}_{2.5}$ while taking into account different driving conditions with closed/open

36 windows (Chaney et al., 2017). A recent study from Sacramento, California has conducted a

37 large-scale multi modal exposure assessment and found ventilation settings to have a significant

38 effect on personal exposure (Ham et al., 2017). Most of the previous studies, however, have

39 focused on the effect of a mode shift from car to active transportation, such as walking and

40 biking (Mueller et al., 2015; Rabl and de Nazelle, 2012). Although potential gains in physical

41 activity may be greater from switching to active travel, it would be more practical to focus on

42 encouraging auto drivers to switch to rail transit. From a public policy point of view, rail transit

43 has a larger contribution to an urban mode share and ridership potential than active transport

44 modes in many urban areas.

46 To fill this important gap, this study investigates the effect of mode shift from automobile to

47 light rail transit (LRT) on personal air pollution exposure. A paired set of personal exposure

48 monitoring instruments was employed to simultaneously measure and compare in-vehicle

49 concentrations and in-LRT concentrations under four plausible commuting scenarios. The

50 simultaneous measurement allowed us to control for daily variations in meteorological condition

51 and background ambient concentrations. To the best of our knowledge, this is one of the first

52 studies to systematically investigate the effect of mode shift from automobile to LRT using

53 simultaneous measurements under four commuting scenarios with varying conditions of

54 ventilation settings and traffic microenvironments.

\section{MATERIAL AND METHODS}

\subsection{Research design}

60 The main objective of this study was to assess the effect of mode shift from automobile to LRT

61 on personal air pollution exposure under real-world conditions. To achieve this objective, the

62 study was designed around three key assumptions: (1) LRT commuters have relatively consistent 
63 personal exposure levels due to traveling in a temperature-controlled transit environment on a

64 fixed route; (2) the effect of switching from automobile to LRT on air pollution exposure is mainly driven by differences in commuter behavior, in particular, ventilation preference and travel route choice; and (3) personal exposure inside of a car and an LRT can be compared using a carefully designed controlled experiment. It should be noted that ambient concentration levels outside of a vehicle or an LRT can be considerably more variable than the concentration levels inside. Ambient concentrations outside of a car and an LRT could be driven by factors unrelated to fleet characteristics or transit microenvironments, such as exposure to cigarette smoking while waiting on a train platform. Therefore, the focus of this study was to understand the effect of a mode shift on in-vehicle and in-LRT exposures.

Under these assumptions, four hypotheses were formulated to test the effect of ventilation and travel route choice. First, it was hypothesized that taking an LRT would yield higher exposure than driving a car under a closed ventilation setting in low traffic condition (Figure 1(1)). This hypothesis was tested by comparing personal exposure while taking an LRT and driving a car with all windows closed and air recirculating $(\mathrm{RC})$ mode on local streets. Local roads were defined as typical neighborhood streets with an annual average daily traffic (AADT) of less than 50,000, avoiding state and federal highways. Second, it was posited that riding an LRT would yield higher exposure than driving a car under a closed ventilation setting in high traffic condition (Figure 1(2)). This hypothesis was tested by comparing personal exposure while taking an LRT and driving a vehicle on highways (AADT more than 50,000) with RC mode and all windows closed. Third, it was assumed that taking a transit would yield lower exposure than driving a car under an open ventilation setting in low traffic condition (Figure 1(3)). This hypothesis was tested by measuring personal exposure while taking an LRT and driving a vehicle on local streets with windows half open on the driver's seats. Lastly, it was hypothesized that transit use would yield lower exposure than car driving under an open ventilation in high traffic condition (Figure 1(4)). This hypothesis was examined by comparing personal exposure while taking an LRTand driving a car on highways with the driver's side windows half open.

92 Based on these hypotheses, four experimental conditions were developed, and each sampling session was carried out by randomly selecting one of the four experimental conditions (Figure 1). 
94 The number of sample run was the same across the experimental conditions - 10 daily samples

95 per mode per experimental condition, yielding a total of 80 daily samples (see Table S1 for the actual sampling schedule). For the field measurements, the technicians were instructed to keep a

97 time-stamped field note using a smartphone app to record any deviation from the specified

98 experiment condition for that sampling session. The field notes were later synchronized with the

99 field measurements using the timestamp, and only the relevant samples were extracted to match

100 the intended experimental condition, minimizing any measurement errors arising from

101 misclassification. For example, for the second hypothesis (a closed ventilation, high traffic

102 condition scenario), only the measurements taken during traveling along highways and

103 expressways were included while any measurements taken outside of the specified sampling

104 condition were excluded from the final sample. For the in-LRT measurement, the fieldnote was

105 also used to exclude any time spent outside of train, e.g., waiting on a train platform. The coding

106 scheme was manually checked against each experimental condition using the video footages and

107 the GPS trajectories simultaneously obtained during the sampling campaign.

108

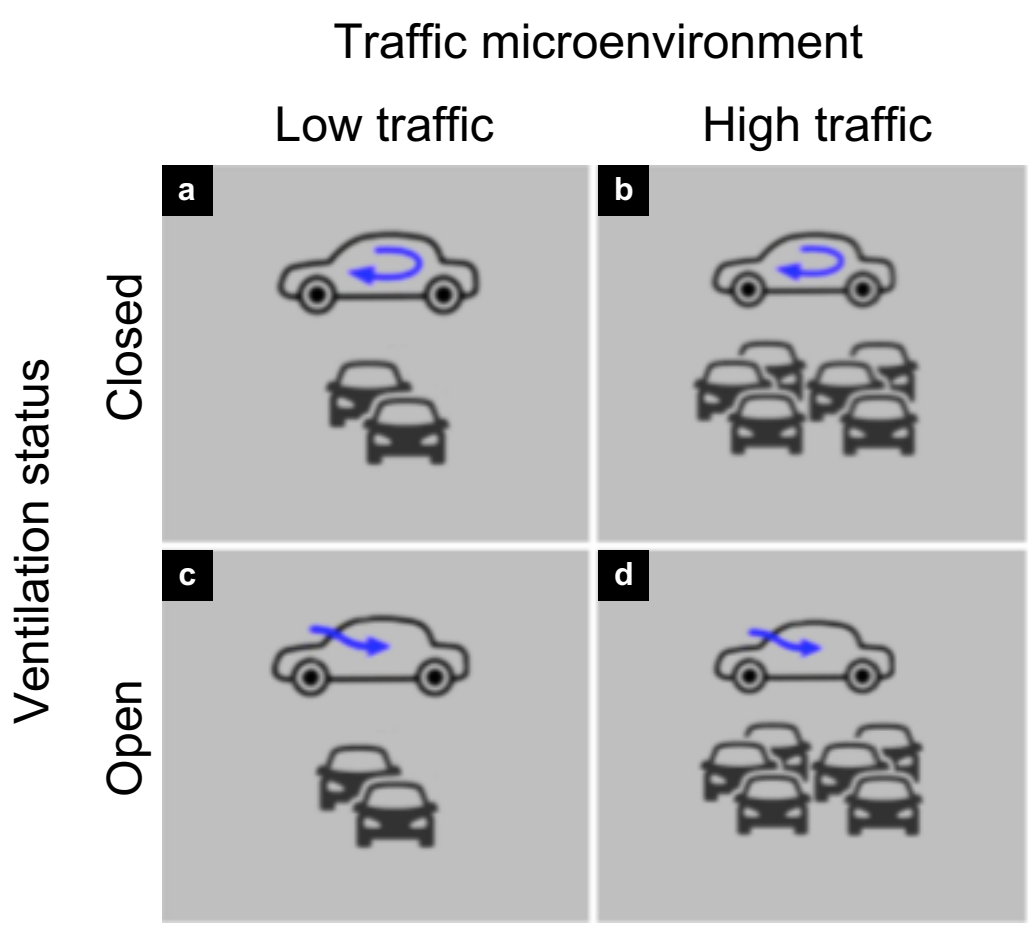

111 Note: a) Condition 1: closed ventilation, low traffic; b) Condition 2: closed ventilation, high traffic; c) Condition 3: open ventilation, low traffic; 112 d) Condition 4: open ventilation, high traffic. 
114 As a robustness check, Monte Carlo simulations were conducted to test the effects of other

115 vehicle-specific factors, including fan strength, vehicle speed, and vehicle age. Overall, it was

116 posited that ventilation conditions and traffic microenvironments will play the key role in

117 determining the modal difference in traffic exposure between car and LRT.

\subsection{Site location and sampling route description}

120 Figure 2 shows the two sampling routes selected for this study. The vehicle and transit routes

121 were carefully selected to represent different transport microenvironments for urban commuters.

122 The vehicle route consists of three highways (I-10, I-110, and I-210) or local streets connecting

123 Culver City and Pasadena. Highway I-10 is the major east-west corridor that connects Los

124 Angeles to Santa Monica, with a daily traffic volume reaching 280,000 vehicles. I-110 is one of 125 the busiest highways in the US with a traffic volume reaching over 328,000 vehicles per day. I-

126210 is also heavily trafficked highways with a traffic volume reaching 298,000 vehicles per day.

127 I-210 is the major east-west corridor that connects Los Angeles and San Bernardino. The vehicle

128 route also includes local streets that run parallel to the highway route, except that they are

129 typically four-lane local roads. The train route was similar to the vehicle route, consisting of

130 three lines of the Los Angeles Metro system (Expo, Red/Purple, and Gold lines). The Expo line

131 is a ground-level light rail transit system connecting downtown Los Angeles to Culver City,

132 eventually reaching downtown Santa Monica in 2016. The Red/Purple line is an underground

133 subway system that connects downtown Los Angeles to North Hollywood. The Gold line is also

134 a ground-level light rail system connecting downtown Los Angeles to Pasadena and to East Los 135 Angeles. 


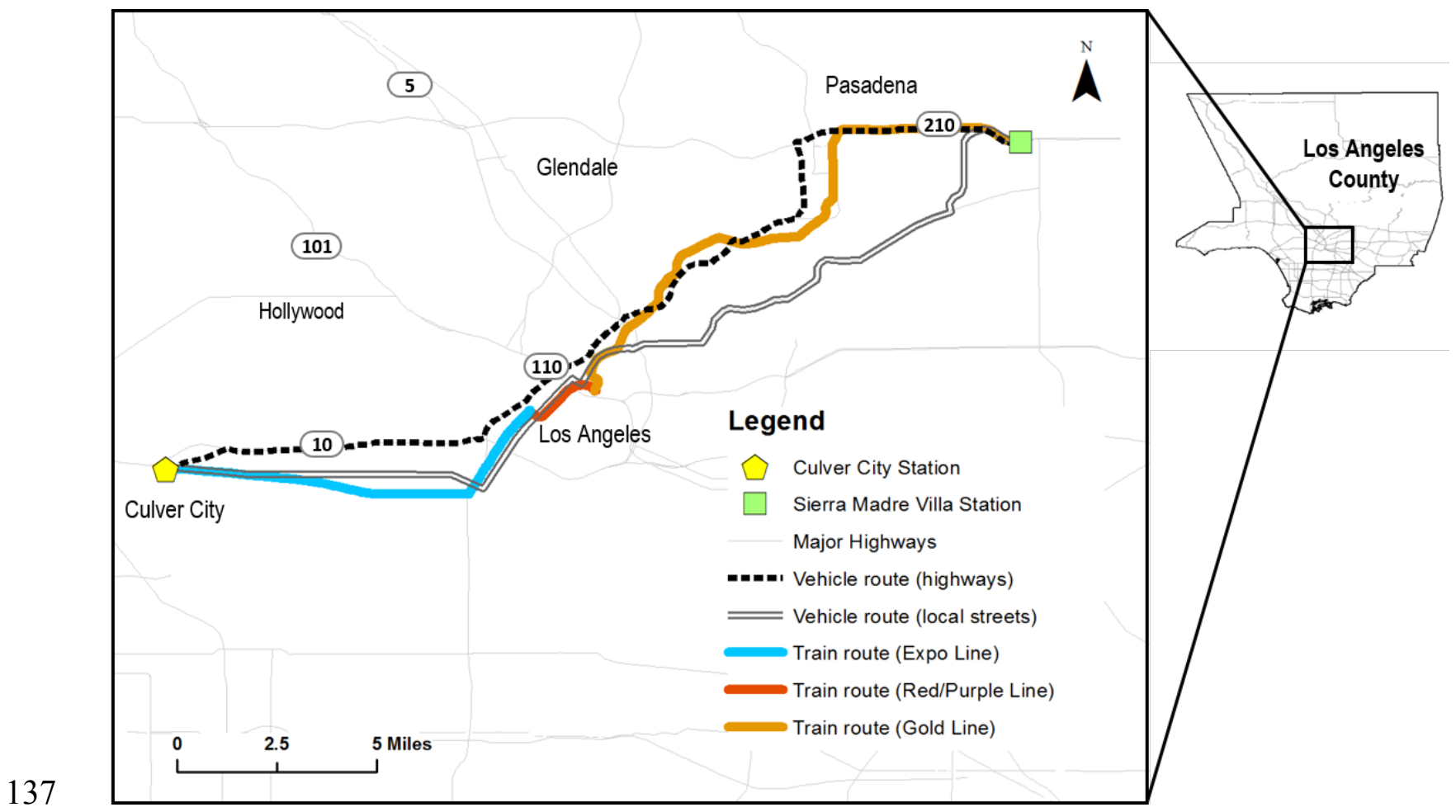

138 Figure 2. Map of sampling routes

\subsection{Study protocol and validation}

142 For the field measurement, two trained technicians simultaneously collected pollutant samples on 143 weekdays from October 13 through November 14, 2014, resulting in over 803 hours of samples

144 (a total of 80 one-way trips). For each daily sampling campaign, two sampling sessions were 145 carried out, consisting of a forward trip from the Culver City Station to the Sierra Madre Villa 146 Station in Pasadena and a backward trip from the Sierra Madre Villa Station to the Culver City

147 Station (Figure 2). Along the sampling routes, one technician drove the car and the other

148 technician took the LRT train simultaneously from 7:00 am through 12:00 pm. The driving route 149 consists of various local streets and three highways (I-10, I-110, and I-210). LRT route consists

150 of two Metro lines: the Expo line and the Gold line. The Red/Purple lines were excluded from

151 the study due to a significantly different environment of subway systems. As is typical with

152 Metro at this time of the year, the transit system was always air conditioned, except for when the 153 train reached the terminal station. 
155 To ensure the validity of the study protocol, a visual survey was conducted to determine whether 156 our experimental conditions reflect the real driving conditions in Los Angeles. Based on the spot 157 visual survey of vehicles via video recordings (Figure S1), it was confirmed that more than one 158 third of the vehicles had their driver's side windows opened at least in half, despite a high 159 ambient temperature (about $30^{\circ} \mathrm{C}$ ) during the spot survey.

161 In addition, a pilot sampling was conducted using portable Aethalometers (AE51, Aethlab ${ }^{\mathrm{TM}}$ ).

162 The pilot measurement indicated that sampling in the morning proved to be more effective in 163 demonstrating differences between the travel modes. Afternoon pollutant concentrations showed 164 little or no differences between the travel modes (Figure S2). This difference can be explained by 165 a combination of lower mixing height and more intense anthropogenic activities in the morning 166 than in the afternoon, a phenomenon commonly known as the 'diurnal effect' (Oke, 1988). The

167 pilot study also confirmed that the ventilation setting offered two contrasting experimental 168 conditions - one that gives the maximum air exchange rate (AER) close to $80-120 \mathrm{~h}^{-1}$ (open169 window), and another that gives the minimum air exchange rate close to $3.5-9.5 \mathrm{~h}^{-1}$ (closed170 window).

\subsection{Instrumentation}

173 Table 1 provides a summary of the instruments used in this study. Two Condensation Particle 174 Counters (CPCs) were employed to measure ultrafine particle (UFP) inside the vehicle and the 175 rail transit cabin (Figure S3). The TSI's CPC 3007 is a handheld device that measures the 176 number of particle size $0.01-1 \mu \mathrm{m}$. This device uses isopropanol as a condensing liquid and can

177 be operated up to 6 hours with one fill-up. For each sampling session, a trained lab technician 178 tested the flow rates of CPCs and performed a zero-check with a high efficiency particulate air 179 filter (HEPA) on a daily basis.

Table 1. Summary of instruments used in the study

\begin{tabular}{lllc}
\hline Device & Manufacturer & Measures & Time resolution \\
\hline CPC 3007 & TSI Inc., MN, USA & Particle count, $10 \mathrm{~nm}-1$ um 10 secs \\
SidePak AM510 & TSI Inc., MN, USA & PM $_{2.5}$ mass concentration & 30 secs \\
Q-trak & TSI Inc., MN, USA & CO, CO2, temp, humidity & 5 secs
\end{tabular}


AE-51 Aethalometer AethLab CA, USA

BT-Q1000XT

SJ 4000

Smartphone
Qstarz, Taipei, Taiwan

SJCAM, Shenzhen, China

Neukadye Timestamped Filed Notes
$\mathrm{BC}$ mass concentration

$1 \mathrm{~min}$

Location (latitude, longitude) $1 \mathrm{sec}$

Video footage

continuous
182

183

Two SidePak AM510 units measured concentrations of particulate matter $\leq 2.5 \mu \mathrm{m}$ in aerodynamic diameter $\left(\mathrm{PM}_{2.5}\right)$ inside the vehicle and the rail transit cabin. The TSI's SidePak is a portable photometric aerosol monitor that uses light scattering method to quantify the airborne concentration of particulate matter size 1.0, 2.5, and $10 \mu \mathrm{m}$. The SidePaks were fitted with a 2.5 $\mu \mathrm{m}$ impactor to control the cut-off size of particles entering the device. A trained lab technician cleaned the impactor and applied new grease after each sampling session. Prior to each sampling session, the SidePak was zero calibrated with the included HEPA filter, and the flow rate was always set to $1.7 \mathrm{~L} / \mathrm{min}$. Because the SidePak devices were factory-calibrated using A1 test dust (Arizona road dust), the actual particles in the air may differ in size, shape, and reflective index. Therefore, a calibration factor of 0.29 was applied for post-processing to reflect the actual $\mathrm{PM}_{2.5}$ particle concentrations. This calibration factor was derived from the previous studies by Lee et al (2007), Jiang et al (2011), and Ott et al (2014) who used a calibration factor of 0.29 for a SidePak monitoring of outdoor aerosols based on a gravimetric comparison.

Two portable Aethalometers (AE51, Aethlab ${ }^{\mathrm{TM}}$ ) were used to measure black carbon concentrations. Aethalometer detects changes in the optical absorption of light transmitted through accumulated black carbon particles captured on a quartz-fiber filter. The air is continuously pumped into the devices, and the devices record concentration levels of black carbon content present in the outside of the vehicle and the transit cabin. The flow rate was always set to $150 \mathrm{ml} / \mathrm{min}$, ATN $<50$. All the devices were updated with the latest Firmware version 706. The AE51 is susceptible to shocks and vibrations, and the measurement can be biased for short sample lengths. Thus, a 1-minute sample interval was selected to minimize biases from noisy data.

Other devices used in this study include a TSI's Q-trak, a GPS, and a portable video camera. Qtrak devices were used to measure $\mathrm{CO}_{2}$, temperature, and humidity. $\mathrm{CO}_{2}$ was measured as a 
tracer gas to determine whether the field technicians were inside or outside the car and the transit

210 cabin. The GPS devices (Qstarz BT-Q1000XT) were used to determine the locational

211 information of the technicians while driving the car and taking the LRT. The GPS data were lost

212 during the time when the technicians was taking the subway and inside the underground stations.

213 However, the lost data account for less than 5\% of the GPS data recorded for each sampling

214 session. To record any unusual events, two portable video cameras (SJCAM SJ4000) were

215 mounted inside the car and clipped on the backpack of the technician. Smartphone-based field

216 note application (Neukadye Time-stamped Filed Notes) was also employed to record

217 starting/ending time and any unusual events. For each sampling campaign, all the devices

218 including the monitoring instruments were synchronized according to the technicians'

219 wristwatch to match the timestamp.

\subsection{Data post-processing and instrument validation}

222 All the raw measurements were carefully post-processed based on a set of procedures (See

223 Section S4 for more detail). In brief, $\mathrm{PM}_{2.5}$ measurements were corrected for biases affected by

224 ambient relative humidity. Light-scattering based nephalometers generally overestimate $\mathrm{PM}_{2.5}$ mass

225 concentrations at higher relative humanity (McMurry et al., 1996). Thus, a correction method used in

226 the previous research (Chakrabarti et al., 2004; Ramachandran et al., 2003) was applied to adjust for

227 the effect of relative humidity on the $\mathrm{PM}_{2.5}$ measurements (Figure S5). BC measurements were post-

228 processed using the Optical Noise-reduction Averaging algorithm developed by Hagler (2011) to

229 dynamically reduce any erroneous readings due to presence of optical and electronic noises

230 (Figure S6). MicroAeth device also tends to underestimate measurement with increased filter

231 loading (Jimenez et al., 2007; Kirchstetter and Novakov, 2007). Thus, the loading effect of the

232 BC measurement was corrected using the empirical function developed by Kirchstetter and

233 Novakov (2007) to reduce the bias introduced when sampling highly light-absorbing particles

234 (Figure S7). Lastly, UFP number concentrations were post-processed to reduce any biases arising 235 from particle coincidence effects (more than one particle in the optical scattering volume at a time)

236 when the number concentrations exceed 100,000 \#/ $\mathrm{cm}^{3}$ (Figure S8) (Westerdahl et al., 2005).

238 To ensure comparability between the measurements for each instrument pair, all the monitoring 239 instruments were collocated for about 30 minutes before and after each sampling campaign. The 
240 instruments were placed on a passenger seat of the technician's vehicle side by side while

241 driving in a normal condition with open-windows. The measurement was taken while the vehicle

242 was driven to and from the daily starting position (a parking lot of the light rail transit station at

243 Culver City), providing a wide range of instrument readings for robust inter-comparison. The

244 collocated measurements were compared using a correlation function, and showed generally high

245 correlations between the two units for all the instrument pairs (Figure S9). The correlations were

246 stronger for the BC and UFP measurements $\left(\mathrm{R}^{2}=0.96\right.$ and 0.97 , respectively) than the

247 correlations for the $\mathrm{PM}_{2.5}$ and $\mathrm{CO}_{2}$ measurements $\left(\mathrm{R}^{2}=0.93\right.$ and 0.94 , respectively). Note that

248 instrument bias have been observed between portable monitors in the past (Matson et al., 2004),

249 and the manufacturer confirmed that the acceptable difference between the two identical units is

250 within $20 \%$. Although the difference between our instruments was within this margin of error, a

251 linear correlation equation was applied to further correct the readings of one instrument

252 compared to another instrument in order to minimize any potential instrument bias and to allow

253 direct comparison of the measurements conducted while driving a car and taking an LRT.

\subsection{Data analysis and robustness check}

256 To compare difference in the measurements between the car and the LRT, the Wilcoxon's signed 257 ranks test was performed. The Wilcoxon's test is a nonparametric test and was preferred over a 258 parametric test (e.g. $t$-test) because of the non-normal distribution of the pollutant samples. In 259 addition, an ANOVA was used to compare the effects of the experimental conditions on the 260 difference $(\Delta)$ in measurements between the paired instruments. The differencing technique was 261 employed in order to minimize daily variations caused by changing meteorological conditions. 262 For example, $\Delta \mathrm{PM}_{2.5}$ was calculated by subtracting the in-vehicle $\mathrm{PM}_{2.5}$ from the in-LRT $\mathrm{PM}_{2.5}$ 263 for each trip. Therefore, the sign of the $\Delta$ represents either the increase $(+)$ or the decrease (-) in 264 air pollution exposure when switching from car to LRT. The absolute value of the $\Delta$ represents 265 the magnitude of change in air pollution exposure when switching from car to LRT.

267 Because this study employed one vehicle, 2006 Ford Focus ST, a robustness check was 268 conducted to test if the results would hold the same for other vehicle types and fleet 269 characteristics. Previous studies have shown that vehicle age, fan strength, and vehicle speed, 270 largely influence in-vehicle exposure (Fruin et al., 2011; Hudda et al., 2012, 2011). Therefore, a 
271 series of Monte Carlo simulations was performed to test the effects of other vehicle-specific

272 parameters on in-vehicle air pollution exposure in comparison to in-LRT exposure.

\section{RESULTS}

\subsection{Measured concentration}

277 Table 2 shows the descriptive summary of the measured concentrations for $\mathrm{PM}_{2.5}, \mathrm{BC}$, UFP, and

$278 \mathrm{CO}_{2}$. For $\mathrm{PM}_{2.5}$, no significant difference was observed under the closed ventilation setting

279 (conditions 1 and 2). However, under the open ventilation setting (conditions 3 and 4), in-LRT

$280 \mathrm{PM}_{2.5}$ exposure was 38 to $40 \%$ lower than in-vehicle exposure $(p<0.001)$. Under the closed

281 ventilation setting, in-LRT BC exposure was 40\% higher than in-vehicle exposure (condition 1,

$282 p<0.01$ ). However, in-LRT BC exposure was $43 \%$ to $68 \%$ lower than in-vehicle exposure under

283 the open ventilation setting (conditions 3 and $4, p<0.01$ ). Similarly, under the closed ventilation

284 setting, in-LRT UFP exposure was 27\% higher (condition $1, p<0.05$ ). Under the open

285 ventilation setting, however, in-LRT UFP exposure was 78\% (condition 3, $p<0.01$ ) to $141 \%$

286 higher (condition 4, $p<0.01$ ) compared to in-vehicle UFP exposure. For $\mathrm{CO}_{2}$, the results were

287 opposite from the results of the above three pollutants. Under the closed ventilation setting

288 (conditions 1 and 2), in-LRT $\mathrm{CO}_{2}$ exposure was lower than in-vehicle exposure. On the other

289 hand, in-LRT $\mathrm{CO}_{2}$ exposure was higher than in-vehicle exposure under the open ventilation

290 setting (conditions 3 and 4).

Table 2. Descriptive summary of the pollutant measurements

\begin{tabular}{|c|c|c|c|c|c|c|c|c|c|c|c|}
\hline \multirow[b]{2}{*}{ Variable } & \multirow{2}{*}{$\begin{array}{l}\text { Experimental } \\
\text { condition }\end{array}$} & \multicolumn{4}{|l|}{ LRT } & \multicolumn{4}{|l|}{ Car } & \multirow[b]{2}{*}{$\% \Delta$} & \multirow[b]{2}{*}{$p$} \\
\hline & & $\begin{array}{l}\text { Mean } \\
(S D)\end{array}$ & Median & Min & Max & $\begin{array}{l}\text { Mean } \\
(\mathrm{SD})\end{array}$ & Median & Min & Max & & \\
\hline \multirow{4}{*}{$\begin{array}{l}\mathrm{PM}_{2.5} \\
\left(\mu \mathrm{g} / \mathrm{m}^{3}\right)\end{array}$} & Condition 1 & $\begin{array}{l}28.75 \\
(17.38)\end{array}$ & 22.76 & 10.22 & 157.27 & $\begin{array}{l}23.61 \\
(9.93)\end{array}$ & 20.01 & 10.18 & 76.71 & $18 \%$ & - \\
\hline & Condition 2 & $\begin{array}{l}31.09 \\
(17.92)\end{array}$ & 27.32 & 6.78 & 96.26 & $\begin{array}{l}27.1 \\
(8.88)\end{array}$ & 26.36 & 10.05 & 74.47 & $13 \%$ & - \\
\hline & Condition 3 & $\begin{array}{l}39.13 \\
(15.93)\end{array}$ & 37.36 & 13.98 & 100.81 & $\begin{array}{l}54.88 \\
(20.14)\end{array}$ & 56.87 & 15.12 & 124.66 & $-40 \%$ & $* * *$ \\
\hline & Condition 4 & $\begin{array}{l}29.81 \\
(21.81)\end{array}$ & 24.49 & 6.78 & 270.32 & $\begin{array}{l}41.2 \\
(18.25) \\
\end{array}$ & 40.51 & 6.94 & 101.35 & $-38 \%$ & *** \\
\hline \multirow{2}{*}{$\begin{array}{l}\mathrm{BC} \\
\left(\mu \mathrm{g} / \mathrm{m}^{3}\right)\end{array}$} & Condition 1 & $\begin{array}{l}2.69 \\
(1.63)\end{array}$ & 2.58 & 0.34 & 9.74 & $1.61(0.9)$ & 1.84 & 0.16 & 4.4 & $40 \%$ & $* * *$ \\
\hline & Condition 2 & $\begin{array}{l}2.57 \\
(1.67)\end{array}$ & 2.22 & 0.22 & 12.69 & $\begin{array}{l}2.02 \\
(1.16)\end{array}$ & 1.65 & 0.35 & 5.99 & $21 \%$ & - \\
\hline
\end{tabular}




\begin{tabular}{|c|c|c|c|c|c|c|c|c|c|c|c|}
\hline & Condition 3 & $\begin{array}{l}1.98 \\
(1.47)\end{array}$ & 1.77 & 0.27 & 11.21 & $\begin{array}{l}2.83 \\
(2.22)\end{array}$ & 2.04 & 0.58 & 31.95 & $-43 \%$ & *** \\
\hline & Condition 4 & $\begin{array}{l}1.8 \\
(1.14)\end{array}$ & 1.68 & 0.18 & 12.24 & $\begin{array}{l}3.02 \\
(2.07) \\
\end{array}$ & 2.81 & 0.55 & 22.66 & $-68 \%$ & $* * *$ \\
\hline \multirow{4}{*}{$\begin{array}{l}\text { UFP } \\
\left(\# / \mathrm{cm}^{3}\right)\end{array}$} & Condition 1 & $\begin{array}{l}23223 \\
(9302)\end{array}$ & 20286 & 9299 & 86590 & $\begin{array}{l}17001 \\
(13399)\end{array}$ & 14390 & 994 & 145900 & $27 \%$ & $* *$ \\
\hline & Condition 2 & $\begin{array}{l}22808 \\
(10252)\end{array}$ & 20923 & 8396 & 85183 & $\begin{array}{l}21791 \\
(11407)\end{array}$ & 19943 & 1860 & 104621 & $4 \%$ & - \\
\hline & Condition 3 & $\begin{array}{l}18833 \\
(8726)\end{array}$ & 17194 & 8854 & 119978 & $\begin{array}{l}33456 \\
(29009)\end{array}$ & 24028 & 5892 & 487258 & $-78 \%$ & *** \\
\hline & Condition 4 & $\begin{array}{l}21674 \\
(8313) \\
\end{array}$ & 20257 & 9219 & 88685 & $\begin{array}{l}52271 \\
(41299) \\
\end{array}$ & 41399 & 7539 & 571277 & $-141 \%$ & $* * *$ \\
\hline \multirow{4}{*}{$\begin{array}{l}\mathrm{CO}_{2} \\
(\mathrm{ppb})\end{array}$} & Condition 1 & $\begin{array}{l}880 \\
(271)\end{array}$ & 866 & 458 & 1773 & $\begin{array}{l}1949 \\
(797)\end{array}$ & 1813 & 701 & 4033 & $-121 \%$ & *** \\
\hline & Condition 2 & $\begin{array}{l}828 \\
(227)\end{array}$ & 776 & 428 & 1558 & $\begin{array}{l}1814 \\
(776)\end{array}$ & 1506 & 759 & 3652 & $-119 \%$ & $* * *$ \\
\hline & Condition 3 & $\begin{array}{l}788 \\
(170)\end{array}$ & 721 & 451 & 1551 & $530(83)$ & 523 & 422 & 1117 & $33 \%$ & $* * *$ \\
\hline & Condition 4 & $\begin{array}{l}762 \\
(176)\end{array}$ & 839 & 428 & 1315 & $566(80)$ & 573 & 431 & 1548 & $26 \%$ & $* * *$ \\
\hline
\end{tabular}

Note: Condition 1: closed ventilation, low traffic; Condition 2: closed ventilation, high traffic; Condition 3: open ventilation, low traffic; Condition 4: open ventilation, high traffic. $P$-values were calculated using Wilcoxon's signed ranks test.

${ }^{*} p<0.05,{ }^{* *} p<0.01, * * * p<0.001$

297 Figure 3 through Figure 6 show the boxplots and the probability density plots for each of the 298 experimental conditions. As shown in the probability density plots (panels in the second row) in 299 Figure 3, in-LRT $\mathrm{PM}_{2.5}$ exposures showed less variance than in-vehicle $\mathrm{PM}_{2.5}$ exposures. Under

300 the closed ventilation setting, the mean difference in PM $_{2.5}$ exposure between LRT and car was

301 small. However, the mean difference becomes larger under the open ventilation setting

302 (conditions 3 and 4). Under the open ventilation setting, the density plots of in-vehicle $\mathrm{PM}_{2.5}$

303 exposures also showed larger variation than in-LRT exposure. 

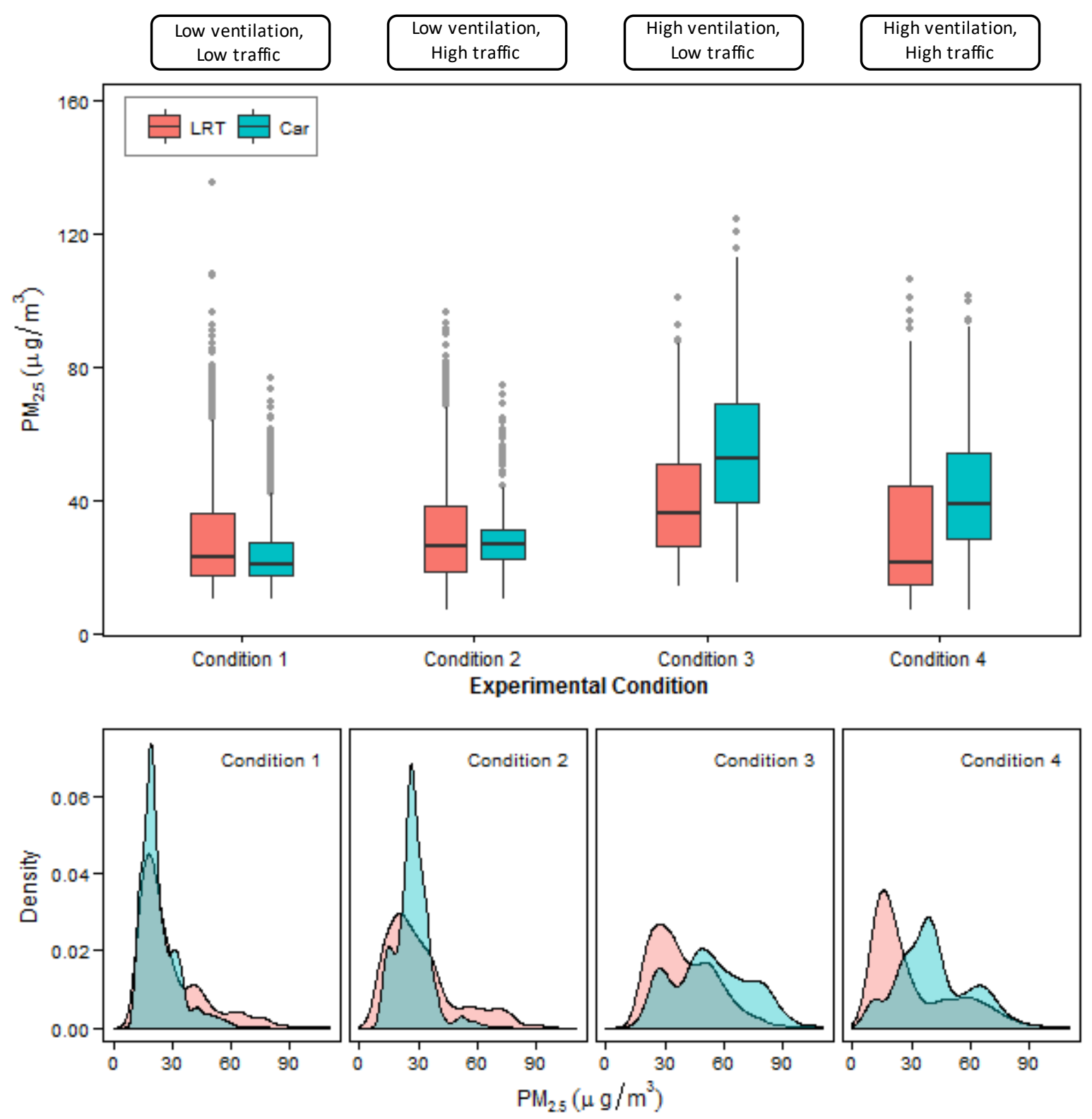

Figure 3. In-LRT and in-vehicle $\mathrm{PM}_{2.5}$ concentrations by experimental condition

Note: Condition 1: closed ventilation, low traffic; Condition 2: closed ventilation, high traffic; Condition 3: open ventilation, low traffic; Condition 4: open ventilation, high traffic. The probability density was plotted using kernel density function.

310 BC exposure results showed similar patterns as the $\mathrm{PM}_{2.5}$ exposures, but the variance was

311 smaller (Figure 4). Distribution patterns between in-LRT and in-vehicle are similar, but for the

312 conditions 3 and 4 , the in-vehicle $\mathrm{PM}_{2.5}$ concentration distribution tends to be wider than that of 313 in-LRT concentrations. 

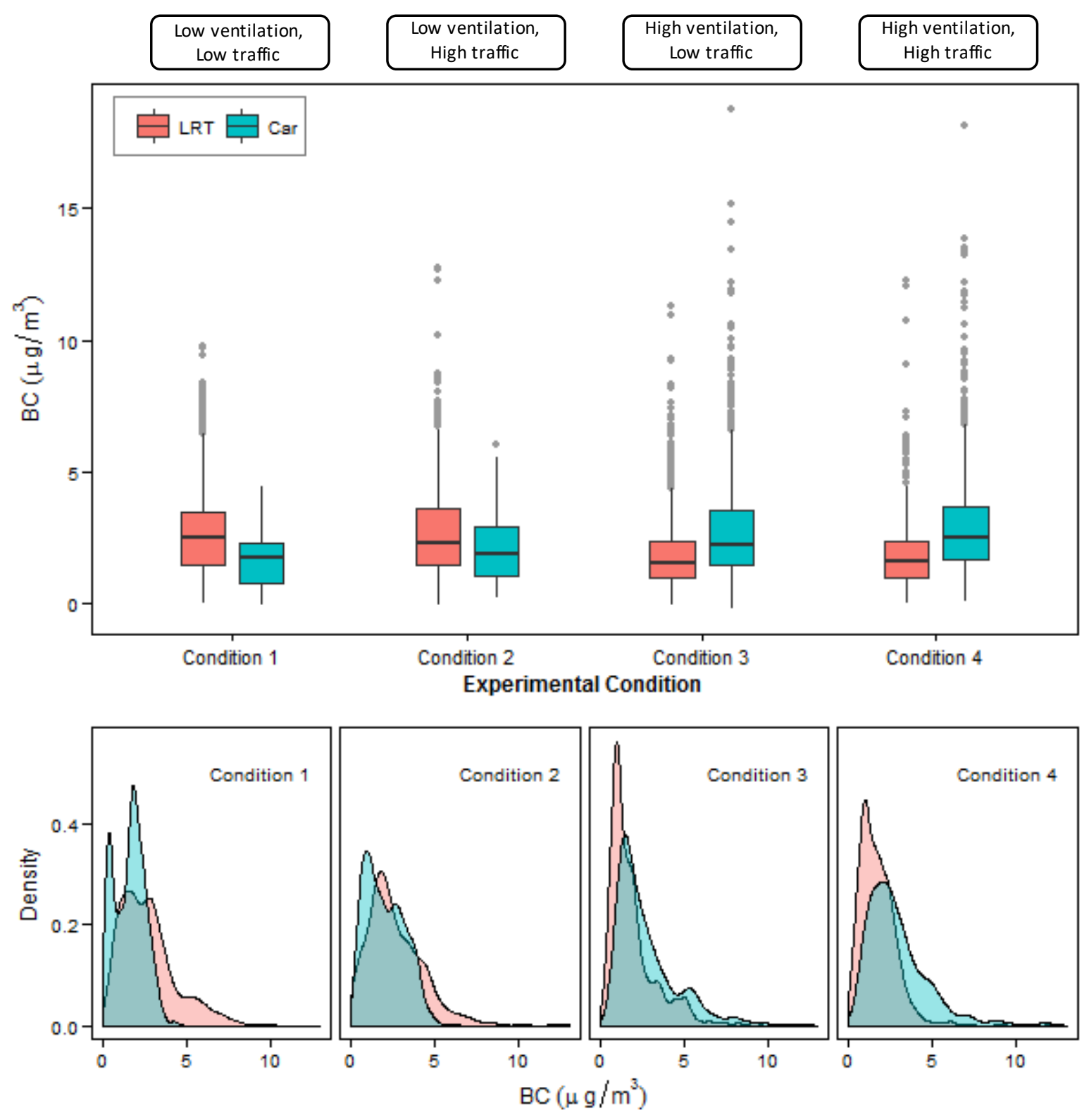

Figure 4. In-LRT and in-vehicle BC concentrations by experimental condition

318 Note: Condition 1: closed ventilation, low traffic; Condition 2: closed ventilation, high traffic; Condition 3: open ventilation, low traffic; Condition 4: open ventilation, high traffic. The probability density was plotted using kernel density function.

321 UFP number concentrations also follow the similar pattern as the previous two pollutants - small 322 variance under the conditions 1 and 2, and high variance under the conditions 3 and 4 (Figure 5). 323 Especially, there is a stark difference in the results for the condition 1 and condition 4. Under the 324 condition 1 which represents a closed-window environment on highways, UFP number 325 concentrations for in-LRT microenvironment have higher mean than for in-vehicle 
326 microenvironment, but the variance looks much the same for both microenvironments. However,

327 under the condition 4, an open-window environment on highways, in-vehicle concentrations

328 show a substantially higher mean and variance than in-LRT concentrations. This suggests that

329 UFP is more sensitive to changes in the microenvironment than other pollutants, and the experimental conditions with varying ventilation setting and travel route choices sufficiently captured the effects of microenvironmental changes on personal exposure.
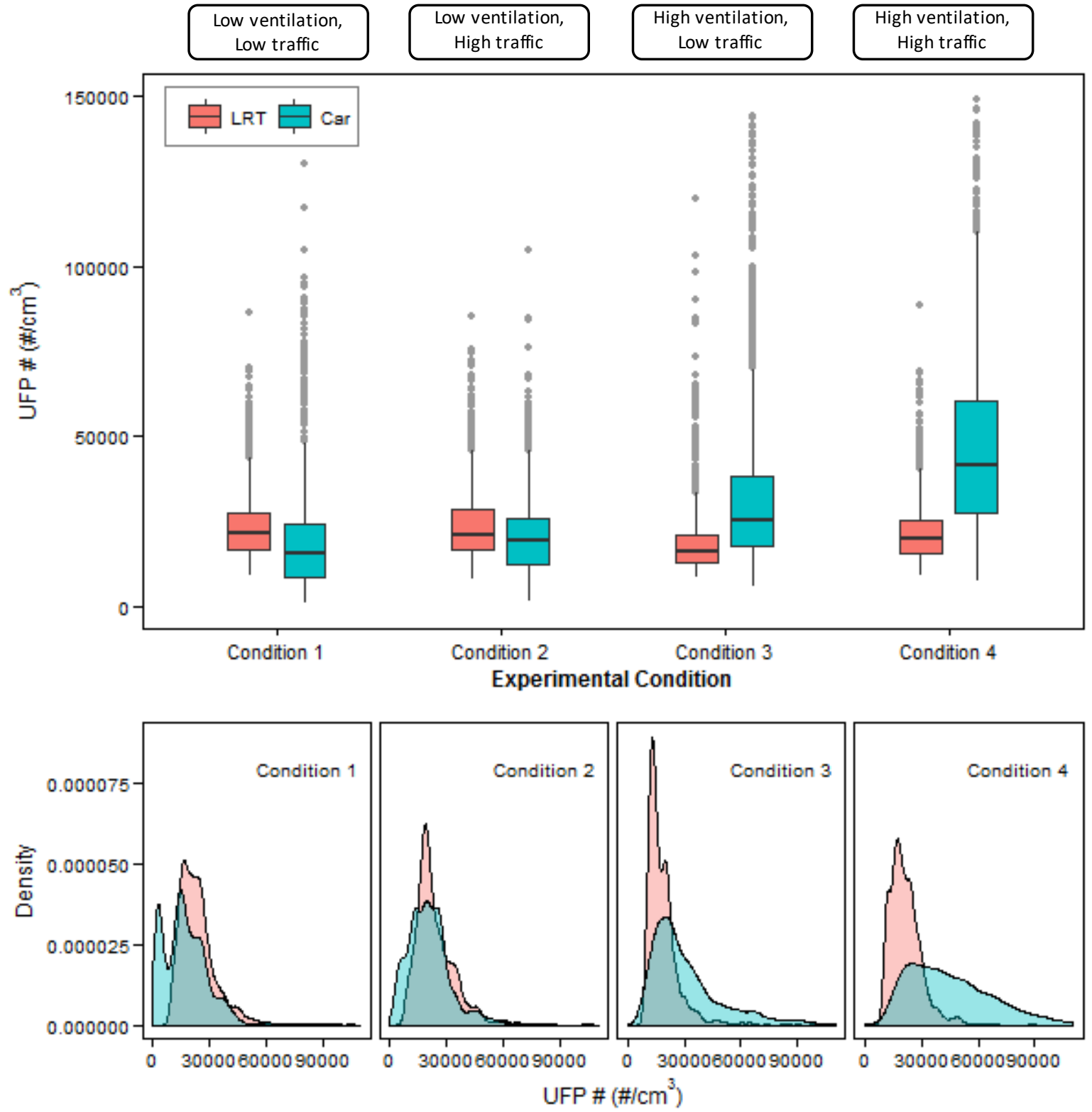

333

334

335

336

Figure 5. In-LRT and in-vehicle ultrafine concentrations by experimental condition

Note: Condition 1: closed ventilation, low traffic; Condition 2: closed ventilation, high traffic; Condition 3: open ventilation, low traffic; Condition 4: open ventilation, high traffic. The probability density was plotted using kernel density function. 
338 Figure 6 shows the boxplots and the probability density plots for the $\mathrm{CO}_{2}$ measurements.

339 Compared to the relatively consistent patterns of the in-LRT concentrations, in-vehicle

340 concentrations show wide variations in terms of sample mean and variance. Under the condition

3411 which represents a closed microenvironment on highways, the mean $\mathrm{CO}_{2}$ concentrations for

342 the in-vehicle environment is substantially higher than that for the in-LRT environment, and are

343 widely distributed from 0 to $4,000 \mathrm{ppb}$. Contrasting this result with the condition 4 which

344 represents an open-window microenvironment, the mean values for the in-vehicle environment

345 are much lower than that for the in-LRT environment with much smaller variance.

346 

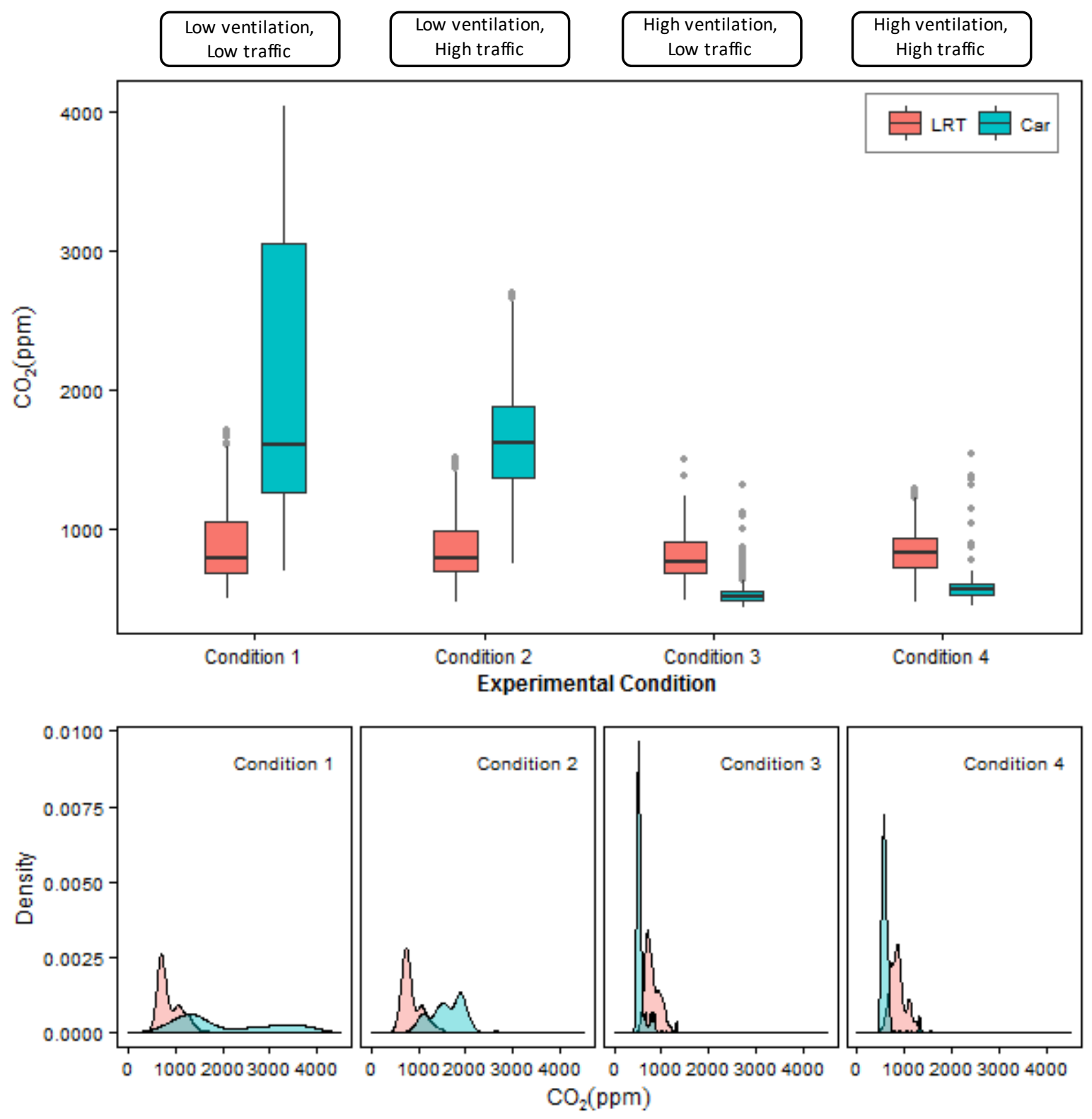

Figure 6. In-LRT and in-vehicle $\mathrm{CO}_{2}$ concentrations by experimental condition

Note: Condition 1: closed ventilation, low traffic; Condition 2: closed ventilation, high traffic; Condition 3: open ventilation, low traffic; Condition 4: open ventilation, high traffic. The probability density was plotted using kernel density function.

\subsection{ANOVA results}

A one-way between subjects ANOVA was performed to test the four hypotheses regarding the exposure differential between LRT and automobile (Figure 7). The results generally confirm the hypotheses. There was a significant effect of ventilation on the mean difference at the $1 \%$ significance level for all the pollutant types $\left(\mathrm{PM}_{2,5}: \mathrm{F}_{(3,3137)}=312.8, p<0.001 ; \mathrm{BC}: \mathrm{F}_{(3,}\right.$, $\left.{ }_{3086)}=327.9, p<0.001 ; \mathrm{UFP \# :} \mathrm{F}_{(3,9294)}=973.2, p<0.001 ; \mathrm{CO}_{2}: \mathrm{F}_{(3,981)}=393.6, p<0.001\right)$. These 
358 results suggest that ventilation and traffic environment settings have significant effects on modal 359 difference in personal exposure. Specifically, the results suggest that under the open ventilation 360 scenario, switching from car to LRT will lead to a significant reduction in exposure levels, 361 indicated by the negative signs of the mean difference in personal exposure in the experimental 362 conditions 3 and 4 . For $\mathrm{PM}_{2.5}$, the experimental condition 4 does not appear to significantly 363 differ from the condition 3. However, for BC and UFP number concentrations, the effects of 364 mode switch is more pronounced in condition 4 than in condition 3 (Condition $3: \mathrm{M}=-0.75, p<$ 365 0.001; Condition 4: $\mathrm{M}=-0.75, p<0.001$ ), suggesting that there is a combined effect of high 366 traffic microenvironment and open ventilation condition. Interestingly, mode switch from car to 367 LRT results in positive mean $\Delta$ in the experimental conditions 1 and 2 across all pollutants, 368 except $\mathrm{CO}_{2}$. This suggests that, under the close ventilation scenario, switching from car to LRT 369 will result in a higher personal exposure. Unlike the results from the conditions 3 and 4, there is 370 little difference in the effects of traffic on mean $\Delta$ when operating in a closed ventilation 371 environment. This result indicates that vehicle cabin and ventilation system provide some form 372 of protection from outside pollutants. 

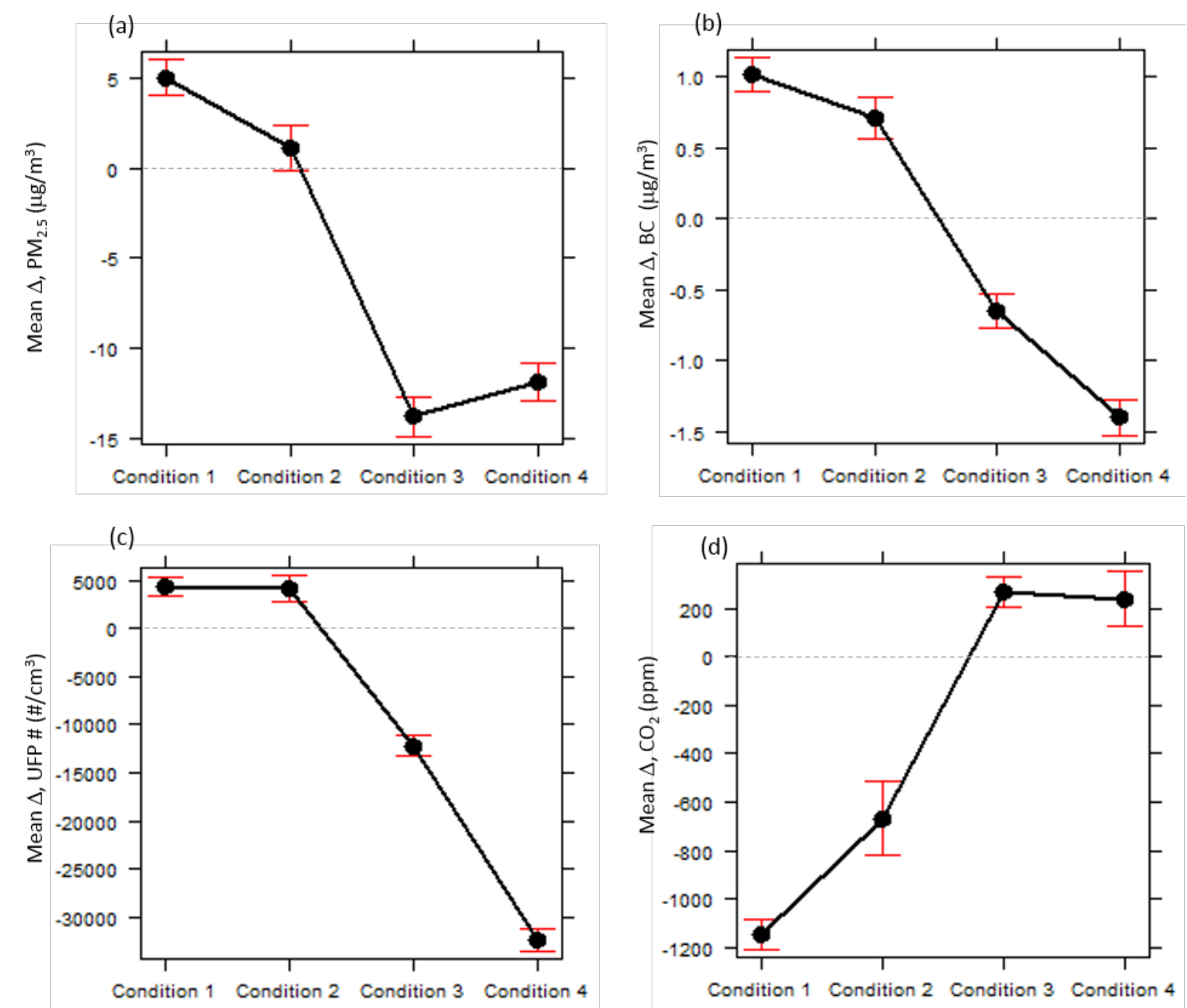

Figure 7. ANOVA results comparing different travel conditions

Note: Condition 1: closed ventilation, low traffic; Condition 2: closed ventilation, high traffic; Condition 3: open ventilation, low traffic; Condition 4: open ventilation, high traffic.

Results of $\mathrm{CO}_{2}$ are the opposite from the results for $\mathrm{PM}_{2.5}, \mathrm{BC}$, and UFP. The mode switch from car to LRT leads to a decrease in exposure when operating in a closed ventilation condition (Conditions 1 and 2) but an increase in exposure when operating in an open ventilation condition

381 (Conditions 3 and 4). This result makes sense because closed ventilation condition inside a

382 vehicle creates an environment where $\mathrm{CO}_{2}$ gets trapped inside a car. A cabin environment inside

383 LRT is generally more ventilated than a tightly sealed private vehicle, therefore, commuters

384 driving a tightly sealed vehicle would experience a decrease in mean $\mathrm{CO}_{2}$ levels when switching 385 mode to LRT. Because $\mathrm{CO}_{2}$ is substantially less toxic than the other three pollutants, the increase 386 in $\mathrm{CO}_{2}$ in a closed ventilation condition is less of a concern for most people, although long-term 
387 exposure to $\mathrm{CO}_{2}$ may have a potential adverse effect and raise a concern for some sensitive 388 population.

\subsection{Robustness check}

391 The robustness of the results was checked against other vehicle-specific factors. Previous studies

392 suggest that in-vehicle I/O ratios significantly differ between RC (air recirculate) and OA

393 (outside air) setting, and developed predictive functions to estimate in-vehicle I/O ratios for 394 various travel conditions (Fruin et al., 2011; Hudda et al., 2012; Hudda and Fruin, 2013; Ott et 395 al., 2008). In a separate analysis, the I/O ratios computed from the predictive functions (adapted 396 from Hudda et al (2012)) were evaluated against the I/O ratios computed from our own sample, 397 and the predictive functions provided reliable estimates of I/O ratios (Table S5). Using the 398 predictive functions, I/O ratios were calculated for different fan settings under RC and OA 399 condition while holding other parameters at their median values (speed $40 \mathrm{mph}$ and vehicle age 400 7). Likewise, the I/O ratios for different vehicle speed and vehicle age were calculated while 401 holding other parameters at the mean (Table S6). The calculated I/O ratios were multiplied by 402 the sample measurement obtained from the experimental conditions 3 and 4 . It was assumed that 403 the sample measurement from the experimental conditions 3 and 4 is representative of the onroad concentrations for both local streets and highways.

Because the pollutant samples followed a log-normal distribution, a log-normal distribution was used to estimate an empirical distribution function from bootstrap sampling of 10,000 iterations under RC (air recirculate) and OA (outside air) condition. A cumulative distribution function with log-scale was plotted to compare the distributional patterns of in-vehicle against in-LRT

411 Bootstrap mean, standard error, and 95\% confidence interval were also calculated to provide a 412 statistical property of the empirical distribution.

\section{Effect of fan strength}

415 Three fan settings, low (20\%), medium (50\%), and high (70\%), were chosen to test the effect of 416 fan strength on in-cabin concentrations. Using the calculated estimates of in-vehicle and in-LRT 417 UFP concentrations, a cumulative distribution function was plotted with log-scale for in-vehicle 
418 concentrations under each of the parameter settings. Representative probability distributions of

419 UFP concentrations are shown in Figure 8. The predicted in-cabin concentrations shows that

420 under RC condition, in-LRT concentrations were expected to be two or three-fold higher in

421 exposure than in-vehicle concentrations. Under OA condition, however, in-vehicle

422 concentrations were expected to be 1.5 to 2 times higher than that of in-LRT concentrations. In

423 both conditions, the increase in fan strength from $20 \%$ to $70 \%$ increased UFP concentrations by

$42428 \%$. The differences in $\mathrm{RC}$ and $\mathrm{OA}$ were larger than the uncertainty associated with the fan

425 strength.

426

(a) Effect of fan strength under air recirculate (RC) condition

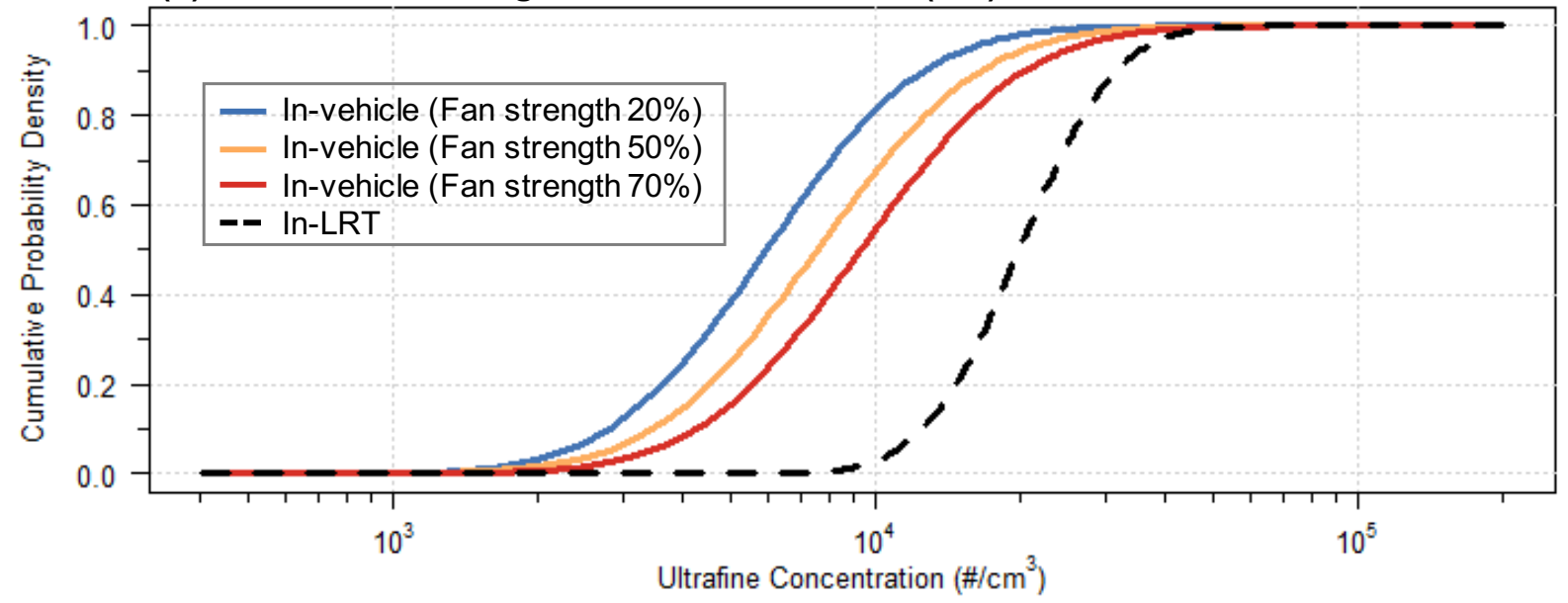

(b) Effect of fan strength under outside air (OA) condition

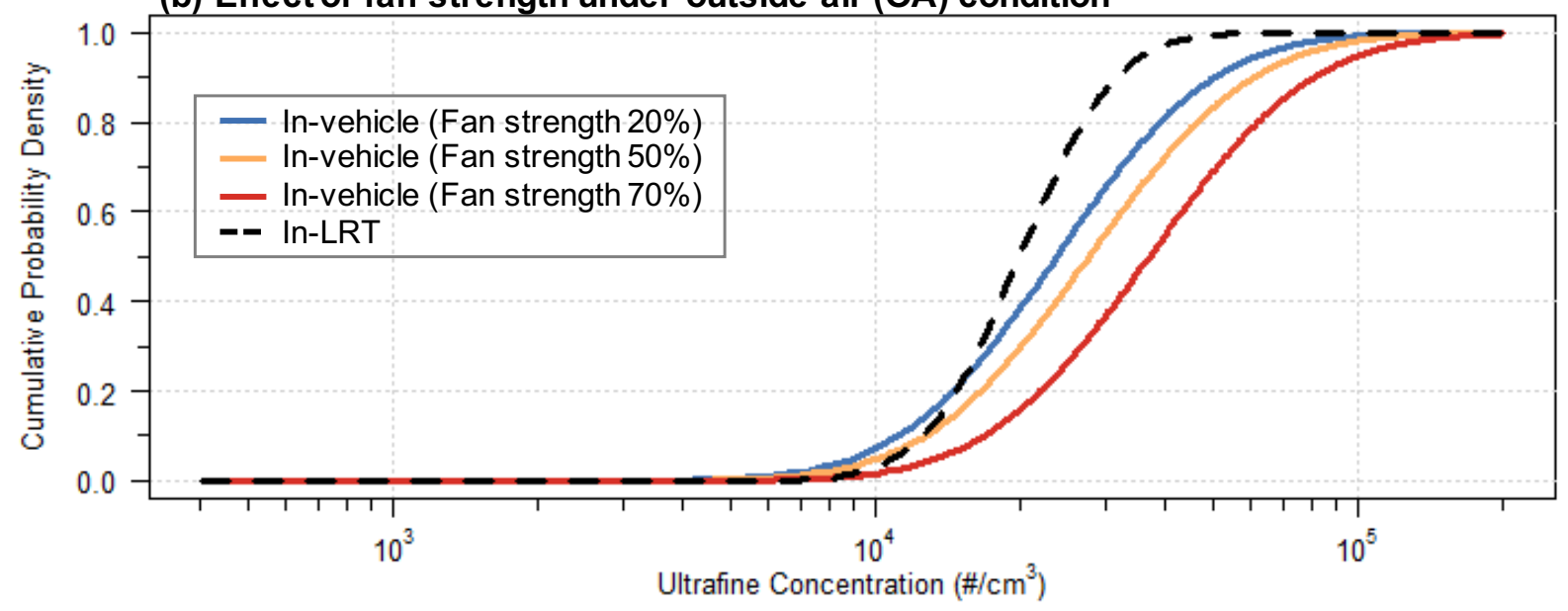

Figure 8. Effect of fan strength on in-vehicle UFP concentrations compared to in-LRT UFP concentrations 


\section{$430 \quad$ Effect of vehicle speed}

431 As shown in Figure 9, three vehicle speeds, low (20 mph), medium (40 mph), and high (60 mph), 432 were arbitrarily chosen to test the effects of vehicle speed on in-cabin UFP concentrations. Under 433 RC condition, in-LRT UFP concentrations were expected to be two to four-times higher than in434 vehicle UFP concentrations. As evident from the probability plot, the effect of vehicle speed on 435 in-vehicle UFP concentrations is more pronounced under the RC condition. The increase in 436 vehicle speed from $20 \mathrm{mph}$ to $60 \mathrm{mph}$ increased the in-vehicle UFP concentrations by $50 \%$.

437 However, in-vehicle concentrations were still lower than in-LRT concentrations across all 438 vehicle speed settings for the RC condition. Comparing this result with the OA condition, only a $439 \quad 1.2$ to 1.7 -fold increase would be expected for in-vehicle concentrations compared to in-LRT 440 concentrations. This means that a driving speed would have little impact on the difference 441 between in-LRT and in-vehicle concentrations if a person typically drives under the OA 442 condition. 
(a) Effect of fan strength under air recirculate (RC) condition

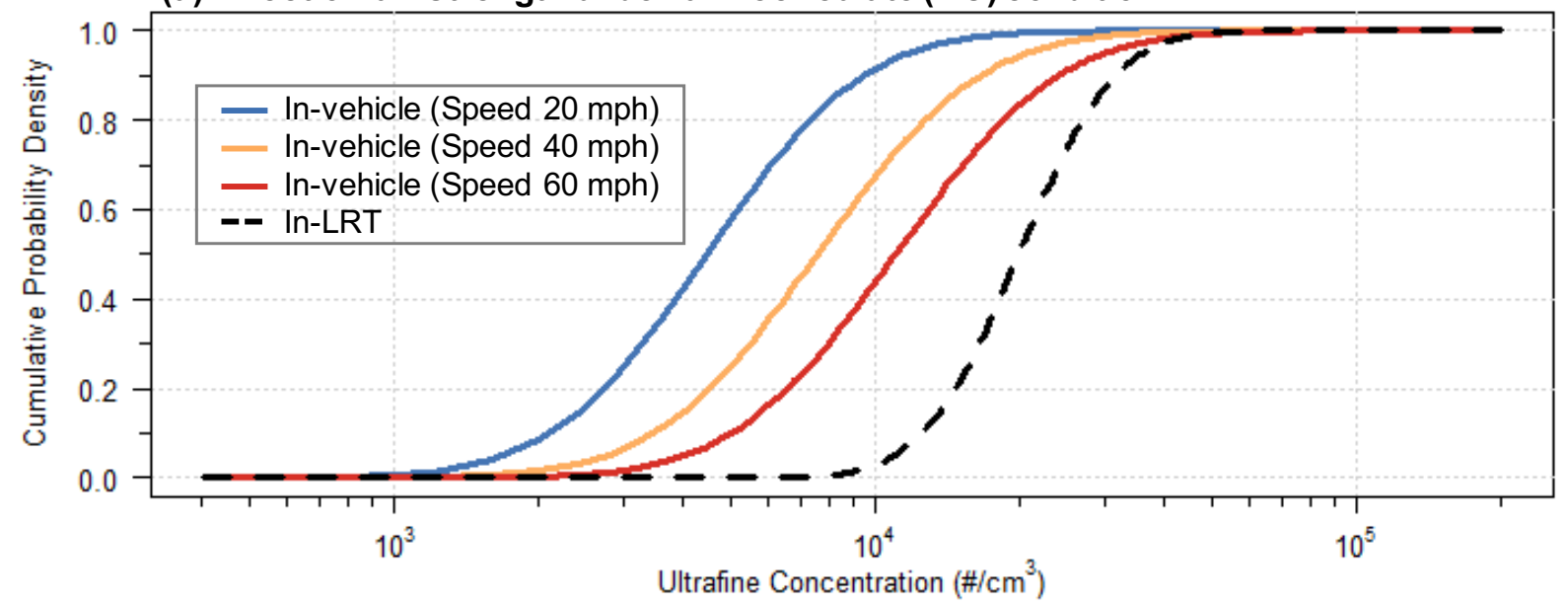

(b) Effect of fan strength under outside air (OA) condition

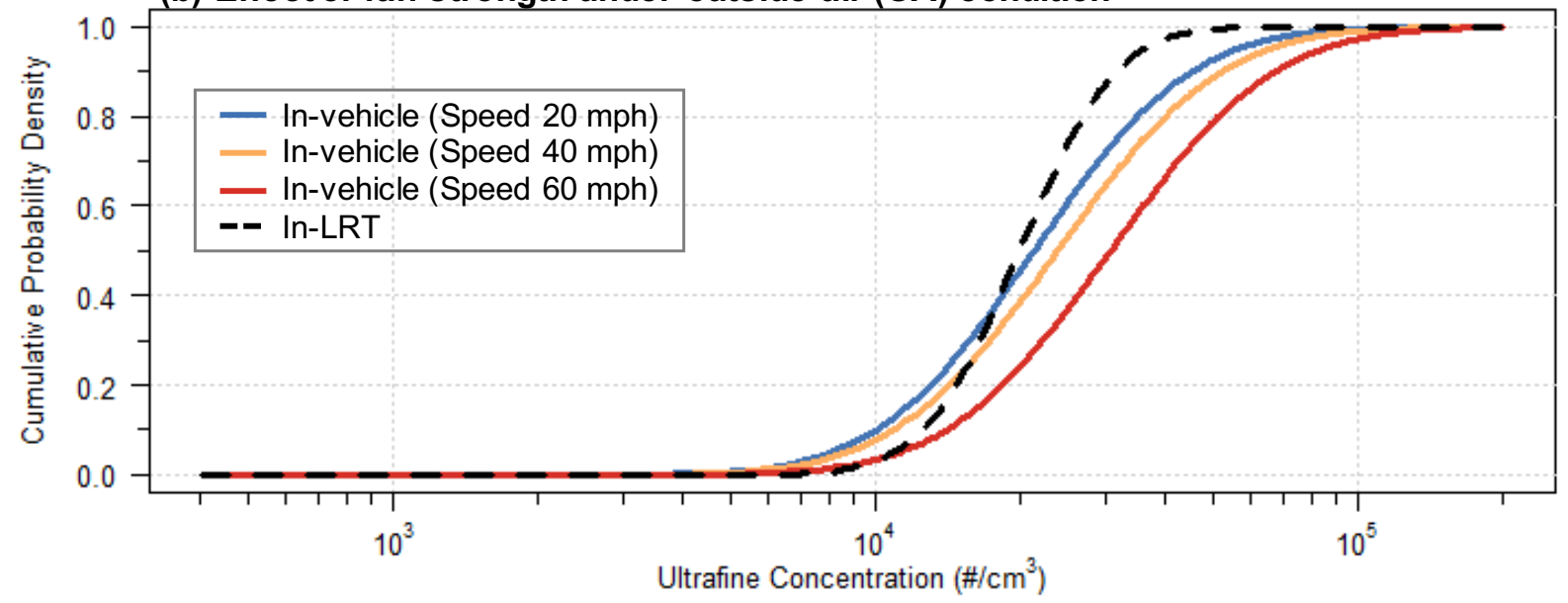

443

444

445

446

Figure 9. Effect of vehicle speed on in-vehicle UFP concentrations compared to in-LRT UFP concentrations

\section{Effect of vehicle age}

To examine the effect of vehicle age on UFP concentrations, three parameters, low (2 years), medium ( 7 years), and high (11 years), were arbitrary chosen. As can be seen from Figure 10, the effect of age is much more pronounced under the RC condition than the OA condition. Under the $\mathrm{RC}$ condition, the increase in vehicle age from 2 to 11 increases in-vehicle UFP concentrations by $46 \%$, whereas the changes in vehicle age under the OA condition have little or no impact on in-vehicle UFP concentrations. Under RC condition, a two to three-fold increase would be expected for in-vehicle UFP exposure compared to in-LRT exposure. Under the OA condition, in-vehicle UFP concentrations are expected to be 1.5 times higher than in-LRT UFP concentrations across the three vehicle ages. 
(a) Effect of fan strength under air recirculate $(\mathrm{RC})$ condition

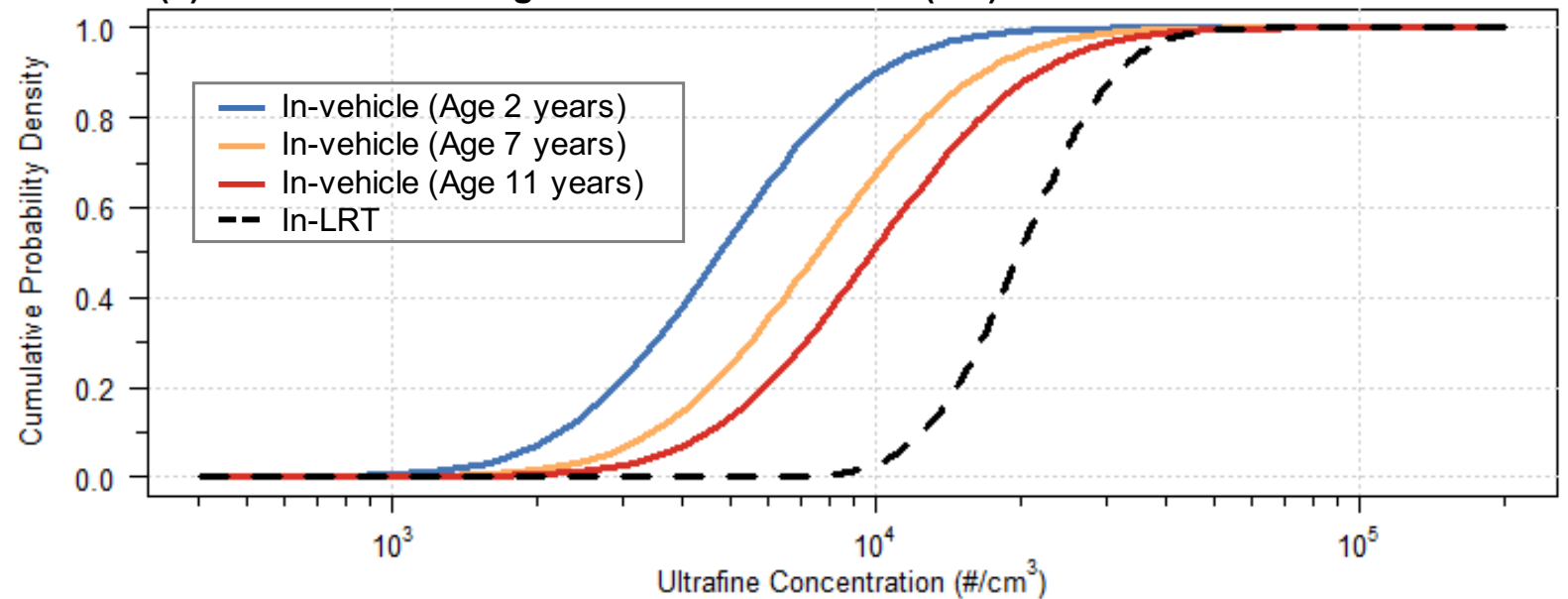

(b) Effect of fan strength under outside air (OA) condition

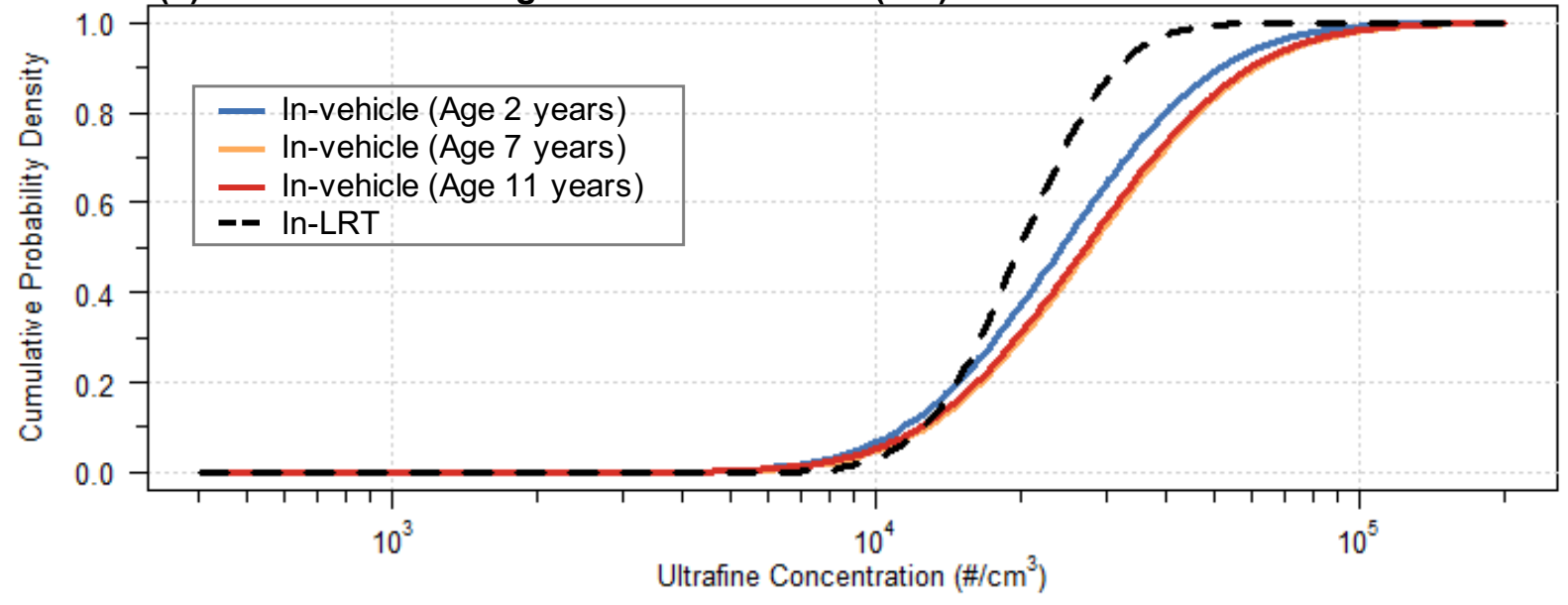

Figure 10. Effect of vehicle age on in-vehicle UFP concentrations compared to in-LRT UFP concentrations

\section{DISCUSSION}

463 The controlled experiment provided evidence that both internal and external microenvironments

464 matter when quantifying the effect of mode switch on personal air pollution exposure. The

465 internal microenvironment is relatively stable for LRT commuting, whereas substantial

466 variations exist when driving a private vehicle. Especially, changing from a closed ventilation to

467 an open ventilation increased in-vehicle exposure by more than two-fold across all pollutant

468 measurements. For example, in-vehicle BC exposure was 21 to 40\% lower than in-LRT exposure

469 under the closed-window environment; however, in-vehicle exposure was 43 to $68 \%$ higher than

470 in-LRT exposure under the open-window environment (Table 2). This finding is consistent with 
471 previous studies of in-vehicle exposure. Hudda \& Fruin (2013) found that I/O ratios for in-

472 vehicle $\mathrm{PM}_{2.5}$ and UFP were three times higher for the OA (outside air intake) condition than for

473 the RC (air recirculate) condition. Knibbs and his colleagues (2010) found that median I/O ratios

474 for in-vehicle UFP ranged between 2 and 4 depending on vehicle models based on a tunnel

475 study. Quiros and his colleagues (2013) also found that UFP concentrations were 40\%-75\%

476 higher when driving with open windows as opposed to driving with closed windows and

477 recirculation on. More recently, Chaney et al (2017) found that in-vehicle $\mathrm{PM}_{2.5}$ exposure was

478 nearly double (192\%) when driving with windows opened compared to driving with windows

479 closed. Ham and his colleagues (2017) also found that ventilation settings of vehicles can reduce

480 in-vehicle exposure by up to $75 \%$.

482 Our results suggest that a simple comparison of in-LRT exposure and in-vehicle exposure would 483 fail to capture the variations in personal exposure for typical urban commuters. The observed 484 difference between in-vehicle and in-LRT exposure ranged between 18 and 140\%. For example, 485 in-LRT BC exposure was generally lower than in-vehicle BC exposure $\left(2.26 \mu \mathrm{g} / \mathrm{m}^{3}\right.$ vs. 2.37 $486 \mu \mathrm{g} / \mathrm{m}^{3}$ ). However, when taking into account fleet characteristics such as ventilation, in-LRT BC 487 exposure was higher than in-vehicle BC exposure when the vehicle was operating under closed 488 ventilation condition $\left(2.69 \mu \mathrm{g} / \mathrm{m}^{3}\right.$ vs. $\left.1.61 \mu \mathrm{g} / \mathrm{m}^{3}\right)$. Except for a few recent studies (Chaney et al., 489 2017; Ham et al., 2017), most previous studies looking at the modal differences in pollutant 490 exposure rarely control for a ventilation condition or make certain assumptions about ventilation 491 condition. For example, Wang and Gao (2011) did not explicitly control for ventilation 492 conditions when measuring $\mathrm{PM}_{2.5}$ and fine particle concentrations for different travel modes, 493 yielding unusually lower $\mathrm{PM}_{2.5}$ mass concentrations (400\% to 1,400\% lower) for automobile 494 compared to all other modes. Briggs and his colleagues (2008), which is frequently cited as the 495 most comprehensive study of commuter exposure, conducted in-vehicle measurement with 496 windows closed while acknowledging that the ventilation status is the most important factor of 497 in-vehicle exposure. Due to substantial variation associated with in-vehicle microenvironments, 498 it is critical to consider the ventilation condition of a vehicle when conducting commuter 499 exposure studies involving automobiles. 
501 Another important factor to consider when quantifying the effect of mode shift would be

502 roadway types. Driving on highways was two to three times more polluted ( $\mathrm{PM}_{2.5}$ and UFP) than

503 driving on local roads when windows were opened (Figure 7). This is perhaps due to the

504 differences in on-road concentrations between local roads and highways (Fruin et al., 2008;

505 Weijers et al., 2004), but there seems to be a combined effect of roadway type and ventilation

506 condition. For example, the effect of switching mode from car to LRT on BC exposure was two

507 to three time larger when roadway type changed from local roads to highways for either closed-

508 window condition or open-window condition (Figure 7). Although the effect of roadway type

509 seems to be less influential than a ventilation condition, the compounding effect of ventilation

510 status and roadway types is a topic that deserves further investigation.

512 Lastly, some other factors, including a vehicle fan strength, a vehicle speed, and a vehicle age,

513 seem to have marginal but potentially influential impact on personal exposure. Results of the

514 robustness check demonstrated that the fan strength had similar effects on in-vehicle exposure

515 across different settings (Figure 8), while the differences due to vehicle speed and vehicle age

516 were larger (two to three-fold) under the RC condition than under the OA condition (Figure 9

517 and Figure 10). Especially, the effect of vehicle age on UFP exposure was almost negligible

518 when driving under the OA condition (Figure 10), suggesting that certain vehicle characteristics

519 are more influenced by internal ventilation condition.

\section{$521 \quad$ Limitations}

522 This study has a few limitations. First, this study did not measure or incorporate minute

523 ventilation rates, which may vary between car drivers and light rail commuters. Ventilation rates

524 are needed to estimate actual inhaled dose and exposure rates. To estimate the health effects of

525 mode switch, further studies will need to incorporate different minute ventilation rates for car

526 drivers and LRT users. Second, the current study only measured concentrations inside a car and

527 an LRT. Because most rail transit users need to travel to and from transit stations, personal

528 exposure during the additional travel to and from the stations may vary significantly from one

529 person to another. Also, personal exposure during the time outside of a car and an LRT can be

530 highly variable. Omission of this extra exposure may have resulted in under-estimation of

531 commuters' exposure. However, with a sufficient sample size, the variation in additional 
532 exposure may follow a stochastic or a random process, in which case, no specific

533 parameterization may be required. Third, the location of the instrument was fixed inside the car

534 and the LRT. It is possible that certain pollutant, e.g. ultrafine particles, may be more affected

535 than other pollutants by the location of the instrumentation, and this could be a fruitful area for

536 further work. Fourth, this study used a light-duty gasoline-fueled vehicle because it is more

537 representative of typical commuters. The Monte Carlo simulation was used to test the effect of

538 other fleet characteristics. However, it would be fruitful to conduct additional experiments using

539 different vehicle types, such as heavy-duty diesel fleet, especially for understanding the effect of

540 mode shift on BC concentrations. Lastly, the sampling campaign took place during one season,

541 and the results may not be representative of all weather conditions. However, the focus of this

542 study was to capture the exposure difference between car and LRT, and the simultaneous

543 measurements allowed us to control for seasonal or meteorological variations that could have

544 confounded the results.

\section{CONCLUSIONS}

548 The results of this study suggest that modal difference in commuter exposure between car and 549 LRT is, in large part, driven by ventilation status and travel microenvironments. Other factors,

550 such as roadway type, vehicle fan strength, vehicle speed, and vehicle age, are likely to influence 551 the modal difference in a more subtle way. The effect of ventilation status on personal exposure 552 was several orders of magnitude greater than the effects due to factors related to fan strength, 553 vehicle speed, and vehicle age. No other observed factors resulted in differences large enough to 554 change the effect of mode shift from car to LRT. Therefore, failure to consider ventilation status 555 could result in an incorrect assessment of commuter exposure to traffic air pollution, potentially 556 leading to misguided policy and research. Further studies will need to examine to what extent 557 incorporation of ventilation status in exposure assessment will affect epidemiological analysis of 558 mid- to long-term health effects of mode shift. 
563

564

565

566 
567 Abbreviations

568 LRT: Light rail transit; PM2.5: Fine particulate matter (diameter $\leq 2.5$ micrometers); UFP:

569 Ultrafine particulate matter (diameter $<0.1$ micrometers); BC: Black carbon; CO2: Carbon

570 dioxide; CF: Correction factor; CPC: Condensation particle counter; GPS: Global positioning

571 system; TRB: Transportation Research Board; HEPA: high efficiency particulate air filter; OA:

572 Outside air intake; RC: Air recirculate; I/O ratios: inside-to-outside ratios; $\mu$ g: microgram; ATN:

573 light attenuation coefficient; ONA: Optical noise-reduction averaging

\section{Acknowledgements}

576 I would like to thank Dr. Kiyoung Lee and his clean air research team at the Seoul National

577 University for loaning their lab instrument for this study. I also thank Dr Scott Fruin for loaning

578 his instrument. I would like to thank Yunkyung Choi who assisted with data collection and

579 Marlon Boarnet, Lisa Schweitzer, Scott Fruin, and Jeongho Moon for their feedback and support.

$581 \quad$ Funding

582 This research was partially supported by funding from the National Research Council for

583 Economics, Humanities and Social Sciences of Korea (NRC) and the Korea Research Institute

584 for Human Settlements (KRIHS). The views expressed in this paper are those of the author and

585 do not reflect the official views of the funding agencies.

\section{Declarations of interest}

None 


\section{REFERENCES}

590 Briggs, D.J., de Hoogh, K., Morris, C., Gulliver, J., 2008. Effects of travel mode on exposures to particulate air pollution. Environ. Int. 34, 12-22.

Brown, B.B., Werner, C.M., Tribby, C.P., Miller, H.J., Smith, K.R., 2015. Transit Use, Physical Activity, and Body Mass Index Changes: Objective Measures Associated With Complete Street Light-Rail Construction. Am. J. Public Health 105, 1468-1474. https://doi.org/10.2105/AJPH.2015.302561

Chakrabarti, B., Fine, P.M., Delfino, R., Sioutas, C., 2004. Performance evaluation of the active-flow personal DataRAM PM2.5 mass monitor (Thermo Anderson pDR-1200) designed for continuous personal exposure measurements. Atmos. Environ. 38, 3329-3340. https://doi.org/10.1016/j.atmosenv.2004.03.007

Chaney, R.A., Sloan, C.D., Cooper, V.C., Robinson, D.R., Hendrickson, N.R., McCord, T.A., Johnston, J.D., 2017. Personal exposure to fine particulate air pollution while commuting: An examination of six transport modes on an urban arterial roadway. PLoS One 12, e0188053. https://doi.org/10.1371/journal.pone.0188053

Chen, Y., Whalley, A., 2012. Green Infrastructure: The Effects of Urban Rail Transit on Air Quality. Am. Econ. J. Econ. Policy 4, 58-97. https://doi.org/10.1257/pol.4.1.58

Fruin, S.A., Hudda, N., Sioutas, C., Delfino, R.J., 2011. Predictive model for vehicle air exchange rates based on a large, representative sample. Environ. Sci. Technol. 45, 3569-3575. https://doi.org/10.1021/es103897u

Fruin, S.A., Westerdahl, D., Sax, T., Sioutas, C., Fine, P.M., 2008. Measurements and predictors of onroad ultrafine particle concentrations and associated pollutants in Los Angeles. Atmos. Environ. 42, 207-219. https://doi.org/10.1016/j.atmosenv.2007.09.057

Hagler, G.S.W., 2011. Post-processing Method to Reduce Noise while Preserving High Time Resolution in Aethalometer Real-time Black Carbon Data. Aerosol Air Qual. Res. 11, 539-546. https://doi.org/10.4209/aaqr.2011.05.0055

Ham, W., Vijayan, A., Schulte, N., Herner, J.D., 2017. Commuter exposure to PM 2.5, BC, and UFP in six common transport microenvironments in Sacramento, California. Atmos. Environ. 167, 335345. https://doi.org/10.1016/j.atmosenv.2017.08.024

Hong, A., Boarnet, M.G., Houston, D., 2016. New light rail transit and active travel: A longitudinal study. Transp. Res. Part A Policy Pract. 92, 131-144. https://doi.org/10.1016/j.tra.2016.07.005

Hudda, N., Eckel, S.P., Knibbs, L.D., Sioutas, C., Delfino, R.J., Fruin, S.A., 2012. Linking in-vehicle ultrafine particle exposures to on-road concentrations. Atmos. Environ. 59, 578-586. https://doi.org/10.1016/j.atmosenv.2012.05.021

Hudda, N., Fruin, S.A., 2013. Models for Predicting the Ratio of Particulate Pollutant Concentrations 
Inside Vehicles to Roadways. Environ. Sci. Technol. https://doi.org/10.1021/es401500c

Hudda, N., Kostenidou, E., Sioutas, C., Delfino, R.J., Fruin, S.A., 2011. Vehicle and driving characteristics that influence in-cabin particle number concentrations. Environ. Sci. Technol. 45, 8691-7. https://doi.org/10.1021/es202025m

Jiang, R., Acevedo-bolton, V., Cheng, K., Klepeis, N.E., Ott, R., Hildemann, L.M., 2011. Determination of response of real-time SidePak AM510 monitor to secondhand smoke, other common indoor aerosols, and outdoor aerosol †. J. Environ. Eng. 13, 1695-1702. https://doi.org/10.1039/c0em00732c

Jimenez, J., Claiborn, C., Larson, T., Gould, T., Kirchstetter, T.W., Gundel, L., 2007. Loading Effect Correction for Real-Time Aethalometer Measurements of Fresh Diesel Soot. J. Air Waste Manage. Assoc. 57, 868-873. https://doi.org/10.3155/1047-3289.57.7.868

Kaur, S., Nieuwenhuijsen, M., Colvile, R., 2005. Pedestrian exposure to air pollution along a major road in Central London, UK. Atmos. Environ. 39, 7307-7320. https://doi.org/10.1016/j.atmosenv.2005.09.008

Kaur, S., Nieuwenhuijsen, M.J., Colvile, R.N., 2007. Fine particulate matter and carbon monoxide exposure concentrations in urban street transport microenvironments. Atmos. Environ. 41, 47814810. https://doi.org/10.1016/j.atmosenv.2007.02.002

Kirchstetter, T.W., Novakov, T., 2007. Controlled generation of black carbon particles from a diffusion flame and applications in evaluating black carbon measurement methods. Atmos. Environ. 41, 1874-1888. https://doi.org/10.1016/j.atmosenv.2006.10.067

Knibbs, L.D., Cole-Hunter, T., Morawska, L., 2011. A review of commuter exposure to ultrafine particles and its health effects. Atmos. Environ. 45, 2611-2622.

Knibbs, L.D., de Dear, R.J., Atkinson, S.E., 2009. Field study of air change and flow rate in six automobiles. Indoor Air 19, 303-313. https://doi.org/10.1111/j.1600-0668.2009.00593.x

Knibbs, L.D., de Dear, R.J., Morawska, L., 2010. Effect of cabin ventilation rate on ultrafine particle exposure inside automobiles. Environ. Sci. Technol. 44, 3546-51. https://doi.org/10.1021/es9038209

Lee, K., Hahn, E.J., Riker, C., Head, S., 2007. Immediate Impact of Smoke-free Laws on Indoor Air Quality. South. Med. J. 100, 885-889.

Matson, U., Ekberg, L.E., Afshari, a., 2004. Measurement of Ultrafine Particles: A Comparison of Two Handheld Condensation Particle Counters. Aerosol Sci. Technol. 38, 487-495. https://doi.org/10.1080/02786820490462200

McMurry, P., Zhang, X., Lee, C., 1996. Issues in aerosol measurement for optics assessments. J. Geophys. Res. 101, 19189-19197. https://doi.org/10.1029/95JD02342 
Morabia, A., Mirer, F.E., Amstislavski, T.M., Eisl, H.M., Werbe-Fuentes, J., Gorczynski, J., Goranson, C., Wolff, M.S., Markowitz, S.B., 2010. Potential Health Impact of Switching From Car to Public Transportation When Commuting to Work. Am. J. Public Health 100, 2388-2391. https://doi.org/10.2105/AJPH.2009.190132

Mueller, N., Rojas-Rueda, D., Cole-Hunter, T., de Nazelle, A., Dons, E., Gerike, R., G??tschi, T., Int Panis, L., Kahlmeier, S., Nieuwenhuijsen, M., 2015. Health impact assessment of active transportation: A systematic review. Prev. Med. (Baltim). 76, 103-114. https://doi.org/10.1016/j.ypmed.2015.04.010

Ott, W., Klepeis, N., Switzer, P., 2008. Air change rates of motor vehicles and in-vehicle pollutant concentrations from secondhand smoke. J. Expo. Sci. Environ. Epidemiol. 18, 312-325. https://doi.org/10.1038/sj.jes.7500601

Ott, W.R., Acevedo-bolton, V., Cheng, K., Jiang, R., Klepeis, N.E., Hildemann, L.M., 2014. Outdoor fine and ultrafine particle measurements at six bus stops with smoking on two California arterial highways — Results of a pilot study. J. Air Waste Manage. Assoc. 64, 47-60. https://doi.org/10.1080/10962247.2013.832712

Quiros, D.C., Lee, E.S., Wang, R., Zhu, Y., 2013. Ultrafine particle exposures while walking, cycling, and driving along an urban residential roadway. Atmos. Environ. 73, 185-194. https://doi.org/10.1016/j.atmosenv.2013.03.027

Rabl, A., de Nazelle, A.J., 2012. Benefits of shift from car to active transport. Transp. Policy 19, 121131. https://doi.org/10.1016/j.tranpol.2011.09.008

Ramachandran, G., Adgate, J.L., Pratt, G.C., Sexton, K., 2003. Characterizing Indoor and Outdoor 15 Minute Average PM 2.5 Concentrations in Urban Neighborhoods. Aerosol Sci. Technol. 37, 33-45. https://doi.org/10.1080/02786820300889

Saxe, S., Cruickshank, H., Miller, E., 2015. Greenhouse Gas Impact of Ridership on Sheppard Subway Line, Toronto, Canada. Transp. Res. Rec. J. Transp. Res. Board 2502, 62-70. https://doi.org/10.3141/2502-08

TRB, 2011. Policy Options for Reducing Energy Use and Greenhouse Gas Emissions from U.S. Transportation, Transportation Research Board. Washington, D.C.

Wang, X.R., Oliver Gao, H., 2011. Exposure to fine particle mass and number concentrations in urban transportation environments of New York City. Transp. Res. Part D Transp. Environ. 16, 384-391. https://doi.org/10.1016/j.trd.2011.03.001

Weijers, E.P., Khlystov, A.Y., Kos, G.P.A., Erisman, J.W., 2004. Variability of particulate matter concentrations along roads and motorways determined by a moving measurement unit. Atmos. Environ. 38, 2993-3002. https://doi.org/10.1016/j.atmosenv.2004.02.045 
691 Westerdahl, D., Fruin, S.A., Sax, T., Fine, P.M., Sioutas, C., 2005. Mobile platform measurements of 692 ultrafine particles and associated pollutant concentrations on freeways and residential streets in Los

693 Angeles. Atmos. Environ. 39, 3597-3610. https://doi.org/10.1016/j.atmosenv.2005.02.034

694 Zuurbier, M., Hoek, G., Oldenwening, M., Lenters, V., Meliefste, K., van den Hazel, P., Brunekreef, B., 695 2010. Commuters' exposure to particulate matter air pollution is affected by mode of transport, fuel 696 type, and route. Environ. Health Perspect. 118, 783-9.

697

698

699 